Research Article

\title{
CTLA-4 gene polymorphisms are associated with obesity in Turner Syndrome
}

Luana Oliveira dos Santos $^{1 *}$ Adriana Valéria Sales Bispo ${ }^{2 *}$, Juliana Vieira de Barros ${ }^{1}$, Raysa Samanta Moraes Laranjeira ${ }^{1}$, Rafaella do Nascimento Pinto ${ }^{1}$, Jaqueline de Azevêdo Silva ${ }^{1}$, Andréa de Rezende Duarte $^{3}$, Jacqueline Araújo ${ }^{4}$, Paula Sandrin-Garcia ${ }^{1}$, Sergio Crovella ${ }^{1}$ (D), Marcos André Cavalcanti Bezerra ${ }^{5}$, Taciana Furtado de Mendonça Belmont ${ }^{6}$, Maria do Socorro Cavalcanti ${ }^{6}$ and Neide $\operatorname{Santos}^{1}$ iD

${ }^{1}$ Departmento de Genética, Universidade Federal de Pernambuco, Recife, PE, Brazil.

${ }^{2}$ Instituto Federal de Educação, Ciência e Tecnologia do Sertão Pernambucano, Campus Serra Talhada, Serra Talhada, PE, Brazil.

${ }^{3}$ Serviço de Genética Medica, Instituto de Medicina Integral Professor Fernando Figueira, Recife, PE, Brazil.

${ }^{4}$ Serviço de Endocrinlogia Pediátrica do Hospital das Clínicas, Universidade Federal de Pernambuco, Recife, PE, Brazil.

${ }^{5}$ Departmento de Biofísica e Radiobiologia, Universidade Federal de Pernambuco, Recife, PE, Brazil.

${ }^{6}$ Instituto de Biociências, Universidade de Pernambuco, Recife, PE, Brazil.

\begin{abstract}
Turner syndrome (TS) is characterized by a set of clinical conditions, including autoimmune/inflammatory diseases and infectious conditions, that can compromise a patient's quality of life. Here we assessed polymorphisms in CTLA-4 +49A/G (rs231775), PTPN22 +1858G/A (rs2476601), and MBL2 -550 (H/L) (rs11003125), -221(X/Y) (rs7096206) and exon 1 (A/O) in women from northeastern Brazil to determine whether polymorphisms within these key immune response genes confer differential susceptibility to clinical conditions in TS. A case-control genetic association study was performed, including 86 female TS patients and 179 healthy women. An association was observed for the $\mathrm{A} / \mathrm{G}$ genotype of $C T L A-4+49 \mathrm{~A} / \mathrm{G}$ in TS patients $(p=0.043$, odds ratio $[\mathrm{OR}]=0.54)$. In addition, an association between the $C T L A-4 \mathrm{G} / \mathrm{G}$ genotype and obesity was detected in TS patients $(p=0.02, \mathrm{OR}=6.04)$. Regarding, the $-550(\mathrm{H} / \mathrm{L})$ polymorphism in the $M B L 2$ promoter, the frequency of the $\mathrm{H} / \mathrm{L}$ genotype was significantly higher in the TS group than healthy controls $(p=0.01, \mathrm{OR}=1.96)$. The $\mathrm{H} / \mathrm{H}$ genotype indicated a protective effect in TS patients $(p=0.01, \mathrm{OR}=0.23)$. No differences were observed in the distribution of $-221(\mathrm{X} / \mathrm{Y}), \mathrm{MBL} 2$ exon 1 variants, and PTPN22 $+1858 \mathrm{G} / \mathrm{A}$ in any assessed groups. CTLA-4 variants are potentially involved in obesity in this cohort of TS patients from northeastern Brazil.
\end{abstract}

Keywords: CTLA-4 gene, immune genes, obesity, polymorphism, Turner syndrome.

Received: October 10, 2017; Accepted: February 27, 2018.

\section{Introduction}

Turner syndrome (TS) is one of the most common chromosomal abnormalities in humans and is characterized by the presence of one $\mathrm{X}$ chromosome and total or partial loss of the second sex chromosome. TS is estimated to affect 1 in every 2500 live female births (Stochholm et al., 2006). Individuals with TS exhibit a set of phenotypic features, including short stature and gonadal dysgenesis. Other clinical conditions, such as osteoporosis, dyslipidemia, obesity and congenital malformations are also observed

Send correspondence to Neide Santos. Departamento de Genética, Universidade Federal de Pernambuco. Av. da Engenharia, s/n, Cidade Universitária, 50740-600, Recife, PE, Brazil. E-mail: neidesantos.ufpe@gmail.com

* These authors contributed equally to this work.
(Ostberg et al., 2005; Carvalho et al., 2010; Bispo et al., 2013; Ríos Orbañanos et al., 2015).

Some studies have reported increased levels of autoantibodies (anti-thyroid peroxidase and anti-glutamic-aciddecarboxylase) in TS patients and an increased risk of developing a range of autoimmune diseases, such as Hashimoto's thyroiditis, type I diabetes mellitus, celiac disease, Crohn's disease, ulcerative colitis, juvenile rheumatoid arthritis, Addison's disease, autoimmune hepatitis, psoriasis, vitiligo, and alopecia (Mortensen et al., 2009; Bianco et al., 2010; Jørgensen et al., 2010; Bakalov et al., 2012). In addition, ovarian insufficiency and absence of a second normal $\mathrm{X}$ chromosome are linked to an increased risk of autoimmune disorders in these patients. However, the underlying pathophysiological mechanisms related to the immune un- 
balance remain to be fully elucidated (Mortensen et al., 2009; Bakalov et al., 2012).

A wide variety of autoimmune/inflammatory diseases and infectious conditions have been associated with a set of genes related to immune regulation, including the tyrosine-protein phosphatase non-receptor type 22 gene (PTPN22), cytotoxic T-lymphocyte-associated protein 4 gene (CTLA4), and mannose-binding lectin (MBL2) (Bottini et al., 2004; Bevilacqua Filho et al., 2012; Katkam et al., 2015). Polymorphisms within these three genes have been analyzed due to their importance in immune balance and homeostasis within the body. Even though a body of evidence indicates immune deregulation processes in TS, only PTPN22 rs2476601 has been assessed in Brazilian TS patients from São Paulo (Southeast region) (Bianco et al., 2010). Furthermore, studies evaluating the role of $M B L 2$ and CTLA-4 polymorphisms in TS and its association with clinical features are lacking.

To understand the role of these key genes in immune misbalance and its consequences, we assessed whether PTPN22, CTLA-4, and MBL2 polymorphisms confer susceptibility to autoimmune conditions or other inflammation-related features in TS patients from Northeast Brazil.

\section{Materials and Methods}

\section{Patients and controls}

This study included 86 patients with cytogenetic diagnosis of TS, who attended at Medical Genetics Service of Institute of Integral Medicine Professor Fernando Figueira and at Pediatric Endocrinology Service of Clinical Hospital of Federal University of Pernambuco. It was proposed as a pilot study. At time of TS diagnosis, patients mean age was 11.48 years old ( $\mathrm{SD} \pm 7.52$ years old), ranging from 0.1 to 33 years. Clinical data shown in the Table 1 were obtained from medical records of each patient. The control group included 179 healthy women from the same geographical region. Their mean age was 34.62 years old $(\mathrm{SD} \pm 13.4$ years old), ranging from 8 to 72 years. Exclusion criteria for the control group included an individuals' history of autoimmune and inflammatory chronic disease, also in close relatives such as parents. All individuals (or their legal responsible) included in this research signed an informed consent term, which followed the Declaration of Helsinki guidelines and presented the approval number from local Ethics Committee (Record: CEP/IMIP N ${ }^{\circ}$ 802/06; CEP/CCS/UFPE N 493/11).

\section{Karyotyping}

Clinical diagnosis of 86 TS patients was confirmed by chromosome analysis in peripheral blood leucocyte. Karyotypes found were as follows: 45, $\mathrm{X}(\mathrm{n}=47,54.65 \%)$; $45, \mathrm{X} / 46, \mathrm{X}, \mathrm{i}(\mathrm{Xq}) \quad(\mathrm{n}=15,17.44 \%) ; \quad 46, \mathrm{X}, \mathrm{i}(\mathrm{Xq}) \quad(\mathrm{n}=4$, $4.65 \%) ; 45, \mathrm{X} / 46, \mathrm{XY}(\mathrm{n}=4,4.65 \%) ; 45, \mathrm{X} / 46, \mathrm{X}, \mathrm{r}(\mathrm{X})(\mathrm{n}=3$,
Table 1 - Clinical characterization of all Turner syndrome patients enrolled in our study.

\begin{tabular}{|c|c|}
\hline Clinical characteristics & $\mathrm{N}$ \\
\hline Short stature & 69 \\
\hline Skeletal abnormalities & $72^{\mathrm{a}}$ \\
\hline Osteopenia/osteoporosis & 4 \\
\hline Sexual infantilism & $100^{\mathrm{b}}$ \\
\hline Primary amenorrhea & 31 \\
\hline Obesity & 9 \\
\hline Dyslipidemia & 5 \\
\hline Autoimmune thyroid disease & 11 \\
\hline Alopecia & 2 \\
\hline Inflammatory diseases & 9 \\
\hline Infectious diseases & 6 \\
\hline Neurological disease & 23 \\
\hline Cardiovascular disease & 17 \\
\hline Renal malformations & 10 \\
\hline Skin diseases & 17 \\
\hline Edema & 35 \\
\hline Mammary hypertelorism & 22 \\
\hline Hearing impairment & 7 \\
\hline Ear malformations & 21 \\
\hline Muscle hypotonia & 3 \\
\hline Arched palate & 7 \\
\hline Nails malformations & 33 \\
\hline Eyes anatomic alterations & 13 \\
\hline Visual impairment & 2 \\
\hline Short and webbed neck & 35 \\
\hline Low posterior hairline & 21 \\
\hline Skin redundancy in the neck & 18 \\
\hline
\end{tabular}

${ }^{a}$ Main clinical conditions are cubitus valgus, pectus scavatum and genu valgus;

${ }^{\mathrm{b}}$ Absent mammary development, absent axillary and pubic hair, hypoplastic uterus and absent ovaries;

3.49); other chromosomal constitutions summed 13 individuals $(15.12 \%)$.

\section{DNA extraction and genotyping}

Genomic DNA was extracted from whole blood using IllustraTM Blood GenomicPrep Mini Spin Kit (GE Healthcare) according to manufacturer's instructions. SNPs selection was based on minimum allele frequency (MAF) of $10 \%$ and/or SNP consequence/function upon gene action. A total of five SNPs were selected distributed as follows PTPN22 +1858G/A (rs2476601) at codon 620, CTLA-4 +49A/G (rs231775) within codon 17 in the first exon and $M B L 2$ promoter region -550(H/L) (rs11003125), -221(X/Y) (rs7096206). Genotyping was performed using TaqMan SNP genotyping assays and Taqman Universal Master Mix (Applied Biosystems ${ }^{\circledR}, \mathrm{CA}$ ) according to 
manufacturer instructions. SNP assessment within $M B L 2$ exon $1(\mathrm{~A} / \mathrm{O})$ was performed using SYBR Green (Qiagen, Hilden, Germany) as previously described (Hladnik et al., 2002). All Sybr Green endpoint PCRs were performed, including all three possible genotypes as positive controls, in a Rotor-Gene 6000 TM apparatus (Corbett Research Mortlake, Sydney, Australia). Ten randomly chosen MBL2 genotyped samples were sequenced in order to double-check the Melting Temperature assay (MTA) results. We found $100 \%$ concordance between sequenced samples and the MTA results.

\section{Statistical analysis}

Statistical analyses were carried out using SNPStats available at http://bioinfo.iconcologia.net/SNPstats_web and R software (https://www.r-project.org/). Hardy-Weinberg equilibrium was tested for each polymorphism by comparing observed with expected frequencies using chi-square $(\chi 2)$ tests. Differences in allele and genotype frequencies from each studied polymorphism in patients and controls were assessed using $\chi^{2}$ or Fisher's exact test. Odds Ratio (OR) and 95\% Confidence Intervals (CI) were also calculated and a $p$-value $<0.05$ was considered statistically significant. Combined alleles for the PTPN22 and $C T L A-4$ genes, haplotypes for the $M B L 2$ gene and a possible association of these combined alleles and haplotype with clinical conditions in TS patients were also assessed. Combined genotypes for the MBL2 gene were assessed by Arlequin version 3.1 software (Excoffier et al., 2005). Fisher's exact test was performed to evaluate difference be- tween combined genotypes in case-control and associations with clinical data in TS group. We compared genotype and allele distribution for all SNPs assessed in this study in TS patients and control group. Posteriorly, we evaluated a possible association of all polymorphic variants with differential presence of autoimmune diseases such as autoimmune thyroid disease and alopecia and other clinical features as follows: obesity, dyslipidemia, inflammatory and infectious conditions in TS patients. Post-hoc (goodness of fit $\chi^{2}$ tests) power analysis was performed with the $\mathrm{G}^{*}$ Power software (version 3.1.9.2, available at http://www.gpower.hhu.de/), with $\alpha$ error probability of 0.05

\section{Results}

\section{PTPN22 and CTLA-4 gene polymorphisms}

The allele and genotype distributions of PTPN22 rs2476601 (G > A) and CTLA-4 rs231775 (A > G) among TS patients and healthy controls are summarized in Table 2. Conformity to Hardy-Weinberg equilibrium (HWE; $p>$ 0.05) was observed in both SNP distributions, and no significant differences were found in the allele and genotype frequencies of these variants in both groups (Table 2).

We did not detect the homozygous A/A genotype of PTPN22 rs2476601 (G > A) in any of the studied groups. A lower frequency of the A allele and G/A genotype was observed in both TS patients and controls (Table 2). No significant association was identified between the assessed SNPs and the presence of any clinical conditions in women with

Table 2 - Genotype and allele distribution of PTPN22 and CTLA-4 gene polymorphisms in TS and controls group.

\begin{tabular}{|c|c|c|c|c|}
\hline Polymorphism & Patients N (\%) & Controls N (\%) & Odds ratio $(95 \% \mathrm{CI})$ & $p$-value \\
\hline \multicolumn{5}{|c|}{ PTPN22 rs2476601 } \\
\hline Allele & 172 & 358 & & \\
\hline G & $170(99 \%)$ & $345(96 \%)$ & 1.00 & \\
\hline A & $2(1 \%)$ & $13(4 \%)$ & $0.31(0.03-1.40)$ & 0.16 \\
\hline Genotype & 86 & 179 & & \\
\hline GG & $84(97.7 \%)$ & $166(92.7 \%)$ & 1.00 & \\
\hline GA & $2(2.3 \%)$ & $13(7.3 \%)$ & $0.30(0.03-1.39)$ & 0.15 \\
\hline AA & $0(0.0 \%)$ & $0(0.0 \%)$ & 0 (0 inf) & 1.00 \\
\hline \multicolumn{5}{|c|}{ CTLA-4 rs231775 } \\
\hline Allele & 172 & 340 & & \\
\hline A & $114(66 \%)$ & $203(60 \%)$ & 1.00 & \\
\hline G & $58(34 \%)$ & $137(40 \%)$ & $0.75(0.50-1.12)$ & 0.17 \\
\hline Genotype & 86 & 170 & & \\
\hline $\mathrm{AA}$ & $41(47.7 \%)$ & $59(34.7 \%)$ & 1.00 & \\
\hline $\mathrm{AG}$ & $32(37.2 \%)$ & $85(50 \%)$ & $0.54(0.29-0.99)$ & $0.043 *$ \\
\hline GG & $13(15.1 \%)$ & $26(15.3 \%)$ & $0.72(0.30-1.66)$ & 0.44 \\
\hline
\end{tabular}

$\mathrm{TS}=$ Turner syndrome; $\mathrm{CI}=$ confidence interval; $p<0.05$ was considered statistically significant.

*Significant difference using Fisher's exact test. 
TS ( $p>0.05$; Fisher's exact test) (Table S1). The power was $80.7 \%$ ( $\alpha$-error $=5 \%$ confidence) to detect a medium effect size $(\mathrm{w}=0.3)$ for $P T P N 22$ genotypes in both patients and controls.

Concerning CTLA-4 rs 231775 , significantly different distributions of genotype frequencies were observed in TS patients compared to the control group. An association was detected for the $\mathrm{A} / \mathrm{G}$ genotype $(p=0.043, \mathrm{OR}=0.54)$, indicating a differential distribution for this SNP in TS patients. The power was $99 \%$ ( $\alpha$-error $=5 \%$ confidence) to detect a medium effect size $(\mathrm{w}=0.3)$ for CTLA4 genotypes comparing patients and controls. Furthermore, when assessing the clinical features of TS and the allele and genotype distribution, we detected an association between the CTLA-4 allele (recessive model: A/A-A/G vs. G/G) and obesity in TS patients $(p=0.02,95 \%$ CI 1.37-26.75, OR=6.04) (Table 3, Table S2).

\section{Combined alleles for PTPN22 and CTLA-4 genes}

The combined alleles of PTPN22 and CTLA-4 and frequencies for both groups are given in Table 5. No significant differences were observed. Furthermore, no significant association was established between the combined alleles and clinical status of TS patients (Table S3).

\section{MBL2 gene polymorphisms}

The MBL2 genotype and allele distributions in TS patients and controls are given in Table 4. All allelic and genotypic frequencies of $M B L 2$ polymorphisms were in HWE in the TS and control groups, except for rs 11003125 $(-550 \mathrm{H} / \mathrm{L})$ in the TS group $(p<0.05)$. The $\mathrm{H} / \mathrm{L}$ genotype frequency was significantly higher in TS patients than controls (overdominant model: $\mathrm{H} / \mathrm{L}$ vs. $\mathrm{L} / \mathrm{L}-\mathrm{H} / \mathrm{H}: p=0.01$, $\mathrm{OR}=1.96,95 \%$ CI 1.11-3.50). Furthermore, the $\mathrm{H} / \mathrm{H}$ genotype indicated a protective effect in TS patients compared to healthy controls (recessive model: $\mathrm{H} / \mathrm{H}$ vs. $\mathrm{L} / \mathrm{L}-\mathrm{H} / \mathrm{L}$ : $p=0.01, \mathrm{OR}=0.23,95 \%$ CI $0.04-0.83$ ). Again, this result cannot be fully explained due to an absence of HWE in this specific group. The power was $99.9 \%$ (5\% confidence) to detect a medium effect size $(\mathrm{w}=0.3)$ for $-550 \mathrm{MBL2}$ genotypes in both groups.
Regarding MBL2 rs7096206 (-221 X/Y), no differences in allele or genotype frequencies were observed between TS patients and controls. The power was 30.5\% (5\% confidence) to detect a medium effect size ( $\mathrm{w}=0.3)$ for -221 $M B L 2$ genotypes when comparing patients and controls. Furthermore, no significant differences were observed in the genotype and allele frequencies of exon 1 variants between TS patients and controls. The power was $91.2 \%(5 \%$ confidence) to detect a medium effect size $(\mathrm{w}=0.3)$ for exon $1 M B L 2$ genotypes when comparing TS patients and controls. In patients with TS, no SNP in the MBL2 gene or promotor region was associated with clinical characteristics (Table S4).

\section{Haplotypes and combined genotypes of MBL2 gene -550 , -221 , and exon 1 variants}

The frequencies of haplotypes and combined genotypes originating from linkage disequilibrium between the MBL2 -550 and -221 promoter region and exon 1 polymorphisms are given in Table 5. Haplotypes were combined in different groups; haplotypes associated with high expression of MBL (LYA, HYA), low production of MBL (LXA), and deficient expression of MBL (LYO, HYO). No significant differences were found in haplotype frequencies between the analyzed groups. Furthermore, no significant association was established among haplotypes and the clinical data of TS patients (Table S5).

Genotypes were classified as high (HYA/HYA, HYA/LYA, and LYA/LYA); low (LXA/LXA, LYA/LXA, HYA/LXA, HYA/HYO, HYA/LYO, and LYA/LYO); and deficient producers of MBL (HYO/HYO, HYO/LXA, $\mathrm{HYO} / \mathrm{LYO}, \mathrm{LYO} / \mathrm{LXA}$, and LYO/LYO). Significant differences were not found between the evaluated groups. Moreover, no significant difference was observed among combined genotypes and the clinical data of TS patients (Table S6).

\section{Discussion}

To date, only a few assays have been performed involving genes linked to innate and adaptive immunity in patients with TS, even though the immune response seems impaired in these patients (Bianco et al., 2010, 2012).

Table 3 - Genotype distribution of CTLA-4 gene polymorphisms in TS group.

\begin{tabular}{|c|c|c|c|c|c|}
\hline Model & Polymorphism & Obesity N (\%) & Non-obesity N (\%) & Odds ratio $(95 \% \mathrm{CI})$ & $p$-value \\
\hline \multirow[t]{5}{*}{ Recessive } & CTLA-4 & & & & \\
\hline & rs 231775 & & & & \\
\hline & Genotype & & & & \\
\hline & AA- AG & $5(55.6 \%)$ & $68(88.3 \%)$ & 1.00 & \\
\hline & GG & $4(44.4 \%)$ & $9(11.7 \%)$ & $6.04(1.37-26.75)$ & 0.023 \\
\hline
\end{tabular}

$\mathrm{CI}=$ confidence interval; $p<0.05$ was considered statistically significant. 
Table 4 - Genotype and allele distribution of MBL2 gene polymorphisms in TS and controls group.

\begin{tabular}{|c|c|c|c|c|c|}
\hline Inheritance Model & Polymorphism & Patients N (\%) & Controls N (\%) & Odds ratio $(95 \% \mathrm{CI})$ & $p$-value \\
\hline & $M B L 2$ rs11003125 & & & & \\
\hline & Allele & 172 & 300 & & \\
\hline & $\mathrm{L}$ & $116(67.0 \%)$ & $198(66.0 \%)$ & 1.00 & \\
\hline & $\mathrm{H}$ & $56(33.0 \%)$ & $102(34.0 \%)$ & $0.93(0.61-1.42)$ & 0.76 \\
\hline \multirow[t]{3}{*}{ Recessive } & Genotype & 86 & 150 & & \\
\hline & $\mathrm{L} / \mathrm{L}-\mathrm{H} / \mathrm{L}$ & $83(96.5 \%)$ & $130(86.7 \%)$ & 1.00 & \\
\hline & $\mathrm{H} / \mathrm{H}$ & $3(3.5 \%)$ & $20(13.3 \%)$ & $0.23(0.04-0.83)$ & $0.01 *$ \\
\hline \multirow[t]{7}{*}{ Overdominant } & Genotype & 86 & 150 & & \\
\hline & $\mathrm{L} / \mathrm{L}-\mathrm{H} / \mathrm{H}$ & $36(41.9 \%)$ & $88(58.7 \%)$ & 1.00 & \\
\hline & $\mathrm{H} / \mathrm{L}$ & $50(58.1 \%)$ & $62(41.3 \%)$ & $1.96(1.11-3.50)$ & $0.01 *$ \\
\hline & $M B L 2$ rs7096206 & & & & \\
\hline & Allele & 172 & 300 & & \\
\hline & $\mathrm{Y}$ & $147(85 \%)$ & $256(85 \%)$ & 1.00 & \\
\hline & $\mathrm{X}$ & $25(15 \%)$ & $44(15 \%)$ & $0.98(0.55-1.73)$ & 1.0 \\
\hline \multirow[t]{7}{*}{ Recessive } & Genotype & 86 & 150 & & \\
\hline & $\mathrm{Y} / \mathrm{Y}-\mathrm{X} / \mathrm{Y}$ & $84(97.7 \%)$ & $144(96.0 \%)$ & 1.00 & \\
\hline & $\mathrm{X} / \mathrm{X}$ & $2(2.3 \%)$ & $6(4.0 \%)$ & $0.57(0.05-3.29)$ & 0.7 \\
\hline & MBL2 Exon 1 & & & & \\
\hline & Allele & 126 & 300 & & \\
\hline & $\mathrm{A}$ & $98(78 \%)$ & $253(84 \%)$ & 1.00 & \\
\hline & $\mathrm{O}$ & $28(22 \%)$ & $47(16 \%)$ & $1.53(0.87-2.66)$ & 0.12 \\
\hline \multirow[t]{3}{*}{ Dominant } & Genotype & 63 & 150 & & \\
\hline & $\mathrm{A} / \mathrm{A}$ & $39(61.9 \%)$ & $108(72 \%)$ & 1.00 & \\
\hline & $\mathrm{A} / \mathrm{O}-\mathrm{O} / \mathrm{O}$ & $24(38.1 \%)$ & $42(28 \%)$ & $1.57(0.80-3.06)$ & 0.14 \\
\hline
\end{tabular}

$\mathrm{TS}=$ Turner syndrome; $\mathrm{CI}=$ confidence interval; $p<0.05$ was considered statistically significant.

*Significant difference using Fisher's exact test.

We included PTPN22 in our analyses due to its importance in the host immune system; this gene encodes LYP, an important negative regulator of $\mathrm{T}$ cell activation (Bottini et al., 2004). Our results indicate an absence of an association between the selected PTPN22 SNP and autoimmunity, inflammatory, and infectious conditions in TS women.

Our results differ from Bianco et al. (2010), who found an association between the same SNP (PTPN22 rs2476601) and the development of autoimmune diseases in TS in another cohort from Southeast Brazil. The frequency of the A allele in women with TS (1.1\%) and healthy controls $(3.6 \%)$, as well as the heterozygote genotype in both groups $(2.3 \%$ and $7.3 \%$, respectively), was lower in our study than that of Bianco et al. (2010). In their study, the frequency of the A allele and heterozygote genotype were $18.3 \%$ and $28.2 \%$ in the TS group, and $9.2 \%$ and $16.1 \%$ in controls, respectively. A disease-associated homozygote genotype was present in $4.2 \%$ of patients and $1.1 \%$ of controls.

This difference between studies could be due to variation in allele frequencies of some disease-associated SNPs in different ethnic groups (Mori et al., 2005), because the Brazilian population exhibits variety in allele distribution. Geographic distributions in Brazil exhibit ethnic disparities, mainly due to the genetic burden of heterogeneous colonization sources (Pena et al., 2009; Coelho et al., 2015).

We also evaluated PTPN22 rs2476601 (G > A) and other clinical features in TS patients, such as obesity, as well as dyslipidemia, given its role in modulating inflammatory conditions. As obesity is a disease characterized by chronic mild inflammation, the concentration of acute phase proteins and cytokines associated with inflammation are higher in obese individuals compared to normal weight individuals (Trayhurn, 2007). However, our analysis did not indicate an association between these clinical manifestations in the TS group, which is similar to a previous study by Salinas-Santander et al. (2016), in which PTPN22 $+1858 \mathrm{G} / \mathrm{A}$ was not associated with differential susceptibility to overweight and the development of obesity in adolescents.

The CTLA-4 $+49 \mathrm{~A} / \mathrm{G}$ polymorphism at exon 1 is involved in the negative regulation of $\mathrm{T}$ cells. Our assay 
Table 5 - Analyses of combined alleles of PTPN22 and CTLA4 genes, haplotypes and genotypes of -550 and -221 promoter region and exon 1 of MBL2 gene in TS patients and controls.

\begin{tabular}{|c|c|c|c|c|c|}
\hline PTPN22 & CTLA4 & Frequencies in TS & Frequencies in controls & $p$-value & OR (95\% C.I.) \\
\hline G & A & 0.6512 & 0.5697 & Reference & 1.00 \\
\hline G & G & 0.3372 & 0.3939 & 0.16 & $0.76(0.52-1.11)$ \\
\hline A & A & 0.0116 & 0.027 & 0.25 & $0.39(0.08-1.93)$ \\
\hline $\mathrm{A}$ & G & 0 & 0.0093 & 1 & 0.00 (-Inf - Inf) \\
\hline \multicolumn{6}{|c|}{ Global haplotype association $p$-value: 0.14} \\
\hline MBL pro & cers and haplotype & Frequencies in TS & Frequencies in controls & $p$-value & OR (95\% C.I.) \\
\hline \multicolumn{6}{|c|}{ High MBL producers } \\
\hline LYA & & 0.3827 & 0.4272 & Reference & 1.00 \\
\hline HYA & & 0.2586 & 0.2694 & 0.89 & $1.04(0.621 .73)$ \\
\hline \multicolumn{6}{|c|}{ Low MBL producers } \\
\hline LXA & & 0.1453 & 0.1467 & 0.69 & $1.12(0.641 .94)$ \\
\hline \multicolumn{6}{|c|}{ Deficient MBL producers } \\
\hline LYO & & 0.1464 & 0.0861 & 0.13 & $1.75(0.853 .60)$ \\
\hline HYO & & 0.0669 & 0.0706 & 0.84 & $1.10(0.452 .67)$ \\
\hline \multicolumn{6}{|c|}{ Global haplotype association $p$-value: 0.63} \\
\hline MBL pro & cers and genotypes & TS group $(n=65)$ & Control $(n=150)$ & $p$-value & OR (95\%C.I.) \\
\hline \multicolumn{6}{|c|}{ High MBL producers } \\
\hline \multicolumn{6}{|c|}{ HYA/HYA } \\
\hline HYA/L & & $27(0.42)$ & $76(0.51)$ & Reference & Reference \\
\hline \multicolumn{6}{|c|}{ LYA/LYA } \\
\hline \multicolumn{6}{|c|}{ Low MBL producers } \\
\hline \multicolumn{6}{|c|}{ LXA/LXA } \\
\hline \multicolumn{6}{|c|}{ LYA/LXA } \\
\hline \multicolumn{6}{|c|}{ HYA/LXA } \\
\hline HYA/H & & $32(0.49)$ & $63(0.42)$ & 0.278 & $1.42(0.74-2.76)$ \\
\hline \multicolumn{6}{|c|}{ HYA/LYO } \\
\hline \multicolumn{6}{|c|}{ LYA/LYO } \\
\hline \multicolumn{6}{|c|}{ Deficient MBL producers } \\
\hline \multicolumn{6}{|c|}{$\mathrm{HYO} / \mathrm{LXA}$} \\
\hline \multicolumn{6}{|c|}{$\mathrm{HYO} / \mathrm{LYO}$} \\
\hline $\mathrm{LYO} / \mathrm{L}$ & & $6(0.09)$ & $11(0.07)$ & 0.558 & $1.53(0.42-5.06)$ \\
\hline \multicolumn{6}{|c|}{$\mathrm{LYO} / \mathrm{LYO}$} \\
\hline $\mathrm{HYO} / \mathrm{H}$ & & & & & \\
\hline
\end{tabular}

showed an association between the rs $231775 \mathrm{G} / \mathrm{G}$ genotype and obesity in the TS group ( $p=0.02)$.

The presence of the $C T L A-4+49 \mathrm{~A} / \mathrm{G}$ variant has been associated with different diseases, and $\mathrm{G} / \mathrm{G}$ individuals may possess CTLA-4 protein with a weak suppression function compared to individuals with the A/A genotype (Chistiakov and Turakulov, 2003). Therefore, increased $\mathrm{T}$-cell activation due to this reduced inhibitory signal to $\mathrm{T}$ cells would be associated with the pathogenesis of several autoimmune/inflammatory diseases, including obesity, as observed with TS patients in the present study. The adipocytes of obese individuals with TS express fewer anti- inflammatory elements and high amounts of proinflammatory factors, leading to a misplaced response in immune cells (Ostberg et al., 2005; Bakalov et al., 2012).

MBL2 polymorphisms and their influence on serum protein levels have been evaluated extensively and found to be associated with recurrent and severe infections (Sumiya et al., 1991; Summerfield et al., 1995), such as tuberculosis (da Cruz et al., 2013) and autoimmune diseases, including celiac disease (Boniotto et al., 2005), systemic lupus erythematosus (Lee et al., 2005), Sjögren's syndrome (Tsutsumi et al., 2001), and autoimmune thyroid disease (AITD) (Bevilacqua Filho et al., 2012). 
Polymorphisms at exon 1 and the promotor region of $M B L 2$ were evaluated in our study due to their role in innate immunity and modulation of the inflammatory response. A relationship between clinical parameters and this genetic variant has not been assessed previously in TS, making our study the first to be performed in women with TS.

No association was found between the MBL2 -221 $(X / Y$ allele) polymorphism and different clinical conditions in TS patients. This $M B L 2$ promoter variation has a significant down-regulating effect on the serum MBL concentration, leading to ineffective clearance of apoptotic cells and the spread of self-antigens, permitting an immune response toward autoimmunity and tissue damage (Bouwman et al., 2006; Araujo et al., 2009). The $Y$ variant is associated with high serum MBL expression (Madsen et al., 1995) and has been involved in susceptibility to the development of different diseases (Lee et al., 2005; da Cruz et al., 2013).

On the other hand, our results revealed significant differences regarding the $-550(\mathrm{H} / \mathrm{L}$ allele) promoter polymorphism between TS patients and controls $(p<0.05)$, revealing a different distribution in both groups.

Notably, in our study population, the $-550 \mathrm{H} / \mathrm{L} M B L 2$ variant was not in HWE, though the power analysis excluded type I and II statistical error. Therefore, we suggest that the TS condition acts upon the allelic distribution, causing deviation from HWE. Although differences in the $M B L 2$ polymorphism distribution have been detected, no significant association was found regarding the MBL2 -550 (H/L allele) variant and clinical data of the TS group.

In summary, even though our study is a pilot study, due to limited number of TS patients and controls included, our results indicate a differential distribution for some polymorphisms within key inflammation-regulating genes in TS patients. The understanding of how key immune genes and its variants are related in TS might help in future therapy strategies. These findings may open up a new potential line of research to improve life's quality in these individuals.

\section{Acknowledgments}

The authors wish to thank the patients, parents, and clinicians for the data. The study was financially supported by the Fundação de Amparo a Ciência e Tecnologia do Estado de Pernambuco (FACEPE - APQ-0638-2.02/12) and by Universidade Federal de Pernambuco (UFPE).

\section{References}

Araujo J, Segat L, Guimarães RL, Brandão LAC, Souza PER, Santos S, Soares TS, Falcão EA, Rodrigues F, Carvalho Jr R et al. (2009) Mannose binding lectin gene polymorphisms and associated auto-immune diseases in type 1 diabetes Brazilian patients. Clin Immunol 131:254-259.

Bakalov VK, Gutin L, Cheng CM, Zhou J, Sheth P, Shah K, Arepalli S, Vanderhoof V, Nelson LM and Bondy CA (2012) Autoimmune disorders in women with turner syn- drome and women with karyotypically normal primary ovarian insufficiency. J Autoimmun 38:315-321.

Bevilacqua Filho CT, Rodrigues FF, Segat L, Fonseca AM, Araujo J, Arahata C, Pontes L, Vilar L, Lima Filho JL and Crovella S (2012) Association of MBL2 gene exon 1 variants with autoimmune thyroid disease in Brazilian patients. Int J Immunogenet 39:357-361.

Bianco B, Verreschi ITN, Oliveira KC, Guedes AD, Galera BB, Galera MF, Barbosa CP and Lipay MVN (2010) PTPN22 polymorphism is related to autoimmune disease risk in patients with Turner syndrome. Scand J Immunol 72:256-259.

Bianco B, Verreschi IT, Oliveira KC, Guedes AD, Barbosa CP and Lipay MV (2012) Analysis of vitamin D receptor gene (VDR) polymorphisms in Turner syndrome patients. Gynecol Endocrinol 28:326-329.

Bispo AVS, Santos LO, Burégio-Frota P, Galdino MB, Duarte AR, Leal GF, Araújo J, Gomes B, Soares-Ventura EM, Muniz MTC et al. (2013) Effect of chromosome constitution variations on the expression of Turner phenotype. Genet Mol Res 12:4243-4250.

Boniotto M, Braida L, Baldas V, Not T, Ventura A, Vatta S, Radillo O, Tedesco F, Percopo S, Montico M et al. (2005) Evidence of a correlation between mannose-binding lectin and celiac disease: a model for other autoimmune diseases. $\mathrm{J}$ Mol Med 83:308-315.

Bottini N, Musumeci L, Alonso A, Rahmouni S, Nika K, Rostamkhani M, MacMurray J, Meloni GF, Lucarelli P, Pellecchia $\mathrm{M}$ et al. (2004) A functional variant of lymphoid tyrosine phosphatase is associated with type I diabetes. Nat Genet 36:337-338.

Bouwman LH, Roep BO and Roos A (2006) Mannose-binding lectin: Clinical implications for infection, transplantation, and autoimmunity. Hum Immunol 67:247-256.

Carvalho AB, Guerra Júnior G, Baptista MT, Faria AP, Marini SH and Guerra AT (2010) Cardiovascular and renal anomalies in Turner syndrome. Rev Assoc Med Bras 56:655-659.

Chistiakov DA and Turakulov RI (2003) CTLA-4 and its role in autoimmune thyroid disease. J Mol Endocrinol 31:21-36.

Coelho AVC, Moura RR, Cavalcanti CAJ, Guimarães RL, Sandrin-Garcia P, Crovella S and Brandão LAC (2015) A rapid screening of ancestry for genetic association studies in an admixed population from Pernambuco, Brazil. Genet Mol Res 14:2876-2884.

Da Cruz HLA, Silva RC, Segat L, Carvalho MSZMG, Brandao LAC, Guimaraes RL, Santos FCF, Lira LAS, Montenegro LML, Schindler HC et al. (2013) MBL2 gene polymorphisms and susceptibility to tuberculosis in a northeastern Brazilian population. Infect Genet Evol 19:323-329.

Excoffier L, Laval G and Schneider S (2005) Arlequin (version 3.0): An integrated software package for population genetics data analysis. Evol Bioinform Online 1:47-50.

Hladnik U, Braida L, Boniotto M, Pirulli D, Gerin F, Amoroso A and Crovella S (2002) Single-tube genotyping of MBL-2 polymorphisms using melting temperature analysis. Clin Exp Med 2:105-108.

Jørgensen KT, Rostgaard K, Bache I, Biggar RJ, Nielsen NM, Tommerup N and Frisch M (2010) Autoimmune diseases in women with Turner's syndrome. Arthritis Rheum 62:658-666.

Katkam SK, Kumaraswami K, Rupasree Y, Thishya K, Rajasekhar L and Kutala VK (2015) Association of CTLA4 
exon-1 polymorphism with the tumor necrosis factor- $\alpha$ in the risk of systemic lupus erythematosus among South Indians. Hum Immunol 77:158-164.

Lee YH, Witte T, Momot T, Schmidt RE, Kaufman KM, Harley JB and Sestak AL (2005) The mannose-binding lectin gene polymorphisms and systemic lupus erythematosus: Two case-control studies and a meta-analysis. Arthritis Rheum 52:3966-3974.

Madsen HO, Garred P, Thiel S, Kurtzhals JAL, Lamm LU, Ryder LP and Svejgaard A (1995) Interplay between promoter and structural gene variants control basal serum level of mannan-binding protein. J Immunol 155:3013-3020.

Mori M, Yamada R, Kobayashi K, Kawaida R and Yamamoto K (2005) Ethnic differences in allele frequency of autoimmune-disease-associated SNPs. J Hum Genet 50:264-266.

Mortensen KH, Cleemann L, Hjerrild BE, Nexo E, Locht H, Jeppesen EM and Gravholt CH (2009) Increased prevalence of autoimmunity in Turner syndrome-influence of age. Clin Exp Immunol 156:205-210.

Ostberg JE, Attar MJ, Mohamed-Ali V and Conway GS (2005) Adipokine dysregulation in turner syndrome: Comparison of circulating interleukin- 6 and leptin concentrations with measures of adiposity and C-reactive protein. J Clin Endocrinol Metab 90: 2948-2953.

Pena SD, Bastos-Rodrigues L, Pimenta JR and Bydlowski SP (2009) DNA tests probe the genomic ancestry of Brazilians. Braz J Med Biol Res 42:870-876.

Ríos Orbañanos I, Vela Desojo A, Martinez-Indart L, Grau Bolado G, Rodriguez Estevez A and Rica Echevarria I (2015) Turner syndrome: From birth to adulthood. Endocrinol Nutr 62:499-506.

Salinas-Santander MA, León-Cachón RB, Cepeda-Nieto AC, Sánchez-Domínguez CN, González-Zavala MA, GallardoBlanco HL, Esparza-González SC and González-Madrazo MA (2016) Assessment of biochemical parameters and characterization of TNF $\alpha-308 \mathrm{G} / \mathrm{A}$ and PTPN22 $+1858 \mathrm{C} / \mathrm{T}$ gene polymorphisms in the risk of obesity in adolescents. Biomed Rep 4:107-111.

Stochholm K, Juul S, Juel K, Naeraa RW and Gravholt CH (2006) Prevalence, incidence, diagnostic delay, and mortality in Turner syndrome. J Clin Endocrinol Metab 91: 3897-3902.

Sumiya M, Super M, Tabona P, Levinsky RJ, Arai T, Turner MW and Summerfield JA (1991) Molecular basis of opsonic defect in immunodeficient children. Lancet 337:1569-1570.

Summerfield JA, Ryder S, Sumiya M, Thursz M, Gorchein A, Monteil MA and Turner MW (1995) Mannose binding protein gene mutations associated with unusual and severe infections in adults. Lancet 345:886-889.

Trayhurn P (2007) Adipocyte biology. Obesity Rev 8:41-44.

Tsutsumi A, Sasaki K, Wakamiya N, Ichikawa K, Atsumi T, Ohtani K, Suzuki Y, Koik T and Sumida T (2001) Mannose-binding lectin gene: Polymorphisms in Japanese patients with systemic lupus erythematosus, rheumatoid arthritis and Sjögren's syndrome. Genes Immun 2:99-104.

\section{Supplementary material}

The following online material is available for this article:

Table S1 - Detailed statistics results for PTPN22 rs2476601 (G/A)

Table S2 - Detailed statistics results for CTLA-4 rs231775 (A/G).

Table S3 - Detailed statistics results for Combined Alleles.

Table S4 - Detailed statistics results for the MBL2 gene and promotor region

Table S5 - Detailed statistics results for the haplotypes (LYA, HYA, LXA, LYO, HYO) of the MBL2 gene.

Table S6 - Detailed statistics results for the genotypes (High MBL expression, Intermediate MBL expression and Low MBL expression) of the $M B L 2$ gene.

Associate Editor: Emmanuel Dias Neto

License information: This is an open-access article distributed under the terms of the Creative Commons Attribution License (type CC-BY), which permits unrestricted use, distribution and reproduction in any medium, provided the original article is properly cited. 